\title{
Research on Performance Evaluation by IDSS Based on AHP
}

\author{
http://dx.doi.org/10.3991/ijoe.v9iS2.2561 \\ Xuelian Tang ${ }^{1}$ \\ ${ }^{1}$ Ningbo Dahongying University, Ningbo City, China
}

\begin{abstract}
Talent resource is the primary resource. There are two sides as the starting point and foothold in this paper. One is how to evaluate the performance of science and technology talents flow by IDSS (Intelligence Decision Supporting System). Another is how to guide the innovation work of science and technology according to the evaluation results. The evaluation index on performance system has hierarchical structure. So AHP (Analytic Hierarchy Process) is applied to evaluate the performance. Evaluation model is established and illustrated by the cases in this paper. It can be seen that the flow of performance is influenced by the growth rate of important scientific and technological achievements. Furthermore, some constructive suggestions are given based on the results of evaluation.
\end{abstract}

Index Terms-IDSS (Intelligence Decision Supporting System), AHP (Analytic Hierarchy Process), Science and technology talents, the flow of performance evaluation.

\section{INTRODUCTION}

“Talent Resources are the primary resources". How to improve the core competitiveness of a country? The key lies in how to cultivate innovative science and technology talents and guide rational flow of science and technology talents to create synergy effects, which has become the consensus on economic development by the world.

Research on the flow of science and technology talents has become the hot spot among domestic and foreign scholars and systematic research theories have been developed. However, applying Intelligence Decision Supporting System (hereinafter referred to as IDSS) to research on the performance evaluation of the flow of science and technology talents still remains rare, domestic scholars made tentative research on this field including Hu-Ruiqing using Composite Index Method[1], Ji-Jianyue using Factor Analysis Method[2-3], and Ye-Chenxuan using Rough Sets Theory[4]. Considering the fact that a lot of data are inaccessible in practical operation which may also contain fuzziness and randomness factors, meanwhile there may exists correlative and mutual constraining relationships among the indicators, therefore, how to conduct scientific analysis and processing on the indicator data is the key to determine whether the results of performance evaluation on the flow of science and technology talents are objective and rational.

Analytic Hierarchy Process (AHP) has distinctive advantages in handling fuzzy problems and methods evaluation on indicator system of articulation relationship. Therefore, this paper introduces AHP Method into the Intelligence Decision Supporting System for the performance evaluation of the flow of science and technology talents in a hope to shed some lights for scholars and decision-makers in relevant fields.

\section{INTRODUCTION OF AHP AND IDSS}

Major headings are to be column centered in a bold font without underline. They need be numbered. "2. Headings and Footnotes" at the top of this paragraph is a major heading.

\section{A. Introduction of AHP}

Analytic Hierarchy Process (AHP) is created by American Operations Researcher A.L.saaty in 1970s. It is a hierarchic and structural decision-making method, and it conducted to analyze multi-indicator system of plans. It also will help decision-makers to turn decision thinking process of complex system into modeling and quantification [7]. By applying this method, the decision-makers will divide complicated problems into several hierarchies and factors, make simple comparisons and calculation among the factors and get the weight of different plans, thus providing basis for choosing the best plans.

\section{B. Introduction of IDSS}

The concept of Intelligence Decision Supporting System (IDSS) was originally proposed by such American scholars as Bonczek in the 1980s. It is a combination of Artificial Intelligence (AI) and Decision Supporting System (DSS). By using Expert System (ES) technology, it enables DSS to better apply human knowledge, such as descriptive knowledge on decision-making problems, process knowledge during the process of decision-making, reasoning knowledge in problem solving. Therefore, it is an assistive decision-making system that helps solve complicated decision-making problems by logical reasoning [8]. The functions enable it to handle both quantitative and qualitative problems.

\section{EVAlUAting PERFORMANCE By IDSS ON AHP}

In the original Intelligent Decision Support System (IDSS) basis, the application of AHP method can make intelligent decision on the performance evaluation plan on flow of science and technology talents, the detailed processes are as follows.

\section{A. Determining Indication System of the General Program}

This paper establishes indication system on the performance evaluation of the flow of science and technology talents .There are four hierarchies, including growth of national disposable income, growth of output of science and technology talents, growth of science and technology talents capital, and optimized allocation of science and technology talents, the details are as the TableI. 
TABLE I.

INDICATION SYSTEM

\begin{tabular}{|c|c|}
\hline Classifica-tion & Details \\
\hline \multirow{2}{*}{$\begin{array}{l}\text { R: Growth of } \\
\text { National } \\
\text { Disposable } \\
\text { Income }\end{array}$} & $\begin{array}{l}\mathrm{R}_{1} \text { : Growth rate of disposable income of urban } \\
\text { residents }\end{array}$ \\
\hline & $\begin{array}{l}\mathrm{R}_{2} \text { : Growth rate }(\mathrm{R} 2) \text { of disposable Income of } \\
\text { rural residents }\end{array}$ \\
\hline \multirow{5}{*}{$\begin{array}{l}\text { O: Growth of } \\
\text { output of } \\
\text { science and } \\
\text { technology } \\
\text { talents }\end{array}$} & O1:Growth rate of patent application acceptance \\
\hline & O2:Growth rate of patent application granting \\
\hline & $\begin{array}{l}\text { O3:Growth rate of important scientific and } \\
\text { technological achievements }\end{array}$ \\
\hline & $\begin{array}{l}\text { O4:Growth rate of transaction value in technical } \\
\text { markets }\end{array}$ \\
\hline & $\begin{array}{l}\text { O5:Growth rate of technical contracts signed in } \\
\text { technical markets }\end{array}$ \\
\hline \multirow{5}{*}{$\begin{array}{l}\text { C: Growth of } \\
\text { science and } \\
\text { technology } \\
\text { talents capital }\end{array}$} & $\begin{array}{l}\text { C1: Growth rate of spending on scientific and } \\
\text { technological activities }\end{array}$ \\
\hline & C2: Growth rate of R\&D spending \\
\hline & $\begin{array}{l}\text { C3: Growth rate of spending on scientific } \\
\text { undertakings }\end{array}$ \\
\hline & $\begin{array}{l}\text { C4: Growth rate of three major spending on } \\
\text { scientific and technological undertakings }\end{array}$ \\
\hline & $\begin{array}{l}\text { C5: Growth rate of spending on educational } \\
\text { undertakings }\end{array}$ \\
\hline \multirow{2}{*}{$\begin{array}{l}\text { D: Optimized } \\
\text { allocation of } \\
\text { science and } \\
\text { technology } \\
\text { talents }\end{array}$} & $\begin{array}{l}\text { D1: Optimization degree of education reception } \\
\text { of science and technology talents }\end{array}$ \\
\hline & $\begin{array}{l}\text { D2:Balance degree of Scientific and technologi- } \\
\text { cal revenue \& scientific and technological } \\
\text { spending }\end{array}$ \\
\hline
\end{tabular}

It can be seen that those indexes are not independent of each other. For example, there exists correlation between the growth rate of patent application acceptance (O1) and the growth rate of patent application granting $(\mathrm{O} 2)$ in the same element group, as well as the growth rate of transaction value in technical markets (O4) and the growth rate of technical contracts signed in technical markets (O5). Another example is that there exists mutually affecting relations between the growth rate of spendings on educational undertakings (C4) and the optimization degree of education reception of science and technology talents (D1). Similarily, there also exist correlation between the elements in the "Growth of capital of science and technology talents" element group, elements in the "Growth of output of science and technology talents" and the Balance degree of Scientific and technological revenue \& scientific and technological spending (D2).

Generally, there exists hierarchy inside the indication system of performance evaluation on science and technology talents. AHP Method is also a good tool for this kind of problems.

\section{B. Analysis on Performance Evaluation Indicators}

Analyzing from the perspective of evaluation indication system, it is much more difficult to obtain direct data of the optimization degree of education reception of science and technology talents (D1) and the Balance degree of Scientific and technological revenue \& scientific and technological spending (D2). Furthermore, there exist problems of inconsistency among data in different years and different regions. Therefore, D1 and D2 were defined as qualitative indicator which can be evaluated and processed with fuzzy language and quantized through Bipolar Scale.

Quantitative indicators can be obtained by accessing to relevant information including local statistical yearbooks and scientific and technological yearbooks. The quantitative indicators include the data of element groups of

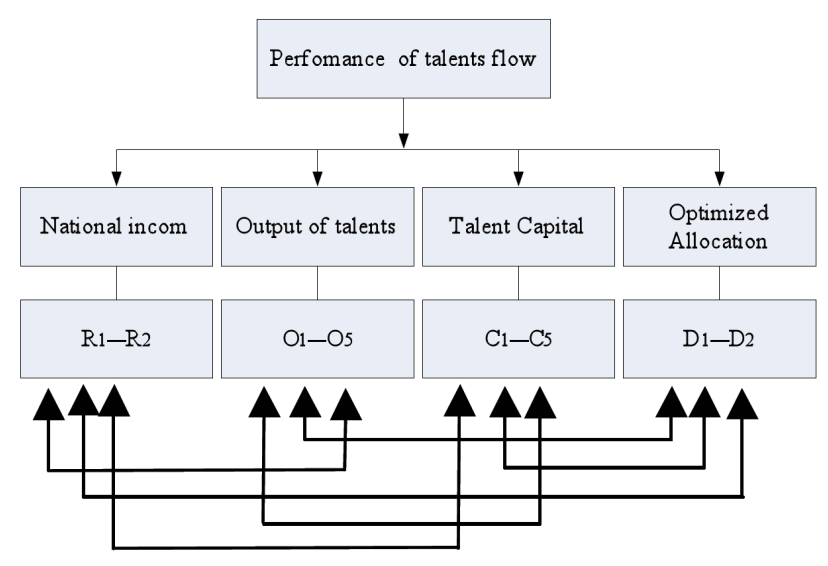

Figure 1. performance evaluation

TABLE II.

RELATION MATRIX

\begin{tabular}{|l|l|l|l|l|l|}
\hline & \multicolumn{1}{|c|}{$\mathbf{R}$} & \multicolumn{1}{|c|}{$\mathbf{O}$} & \multicolumn{1}{c|}{ C } & \multicolumn{1}{|c|}{ D } & Priority Vector \\
\hline $\mathbf{R}$ & 1.0 & 1.0 & 1.0 & $1 / 3$ & 0.167 \\
\hline $\mathbf{O}$ & 10 & 1.0 & 1.0 & $1 / 3$ & 0.167 \\
\hline $\mathbf{C}$ & 1.0 & 1.0 & 1.0 & $1 / 3$ & 0.167 \\
\hline $\mathbf{D}$ & 3.0 & 3.0 & 3.0 & 1.0 & 0.500 \\
\hline
\end{tabular}

growth of national disposable income, growth of output of science and technology talents, growth of science and technology talents capital.

After qualitative indicators being quantified, it can be nondimensionalized through $0-1$ linear transformation with the quantitative indicators. Due to limited length of this paper, the specific procedures and formulas can be referred to the documents ${ }^{[7]}$.

\section{Establishing Performance Evaluation Model}

For the above indicators, there are two kinds of planhierarchy data. One is quantitative data of engineering analysis; another is subjective judgment of the plans made by expert basis on comparison and analysis. The system will receive the above two kinds of data respectively to compare and analyze among the programs.

According to indication systems, the model of performance evaluation on the flow of science and technology talents has been created, as shown in Figure 1.

Figure 2.

\section{A Case in Zhejiang}

The calculation process of this model will be discussed. The following content will combined with the example of performance evaluation in some city of Zhejiang Province.

Firstly, establish relation matrix among the four element groups, as shown in Table II.

Secondly, calculate the relative importance relations in each element groups and that with elements of other element groups through Super Decisions which is kind of AHP software at the network layer. Then we built the unweighted super matrix, which can be obtained by further calculating. The values of the matrix stabilized after many times of transformation, the long-term stable matrix can be obtained, as shown in Table III. 
TABLE III.

LONG-TERM STABLE MATRIX \begin{tabular}{|l|l|l|l|l|l|l|l|l|l|l|l|l|l|l|}
\hline & $\mathrm{R}_{1}$ & $\mathrm{R}_{2}$ & $\mathrm{O}_{1}$ & $\mathrm{O}_{2}$ & $\mathrm{O}_{3}$ & $\mathrm{O}_{4}$ & $\mathrm{O}_{3}$ & $\mathrm{C}_{1}$ & $\mathrm{C}_{2}$ & $\mathrm{C}_{3}$ & $\mathrm{C}_{4}$ & $\mathrm{C}_{3}$ & $\mathrm{D}_{1}$ & $\mathrm{D}_{2}$ \\
\hline $\mathrm{R}_{1}$ & 0.050 & 0.050 & 0.050 & 0.050 & 0.050 & 0.050 & 0.050 & 0.050 & 0.050 & 0.050 & 0.050 & 0.050 & 0.050 & 0.050 \\
\hline $\mathrm{R}_{2}$ & 0.062 & 0.062 & 0.062 & 0.062 & 0.062 & 0.062 & 0.062 & 0.062 & 0.062 & 0.062 & 0.062 & 0.062 & 0.062 & 0.062 \\
\hline $\mathrm{O}_{1}$ & 0.071 & 0.071 & 0.071 & 0.071 & 0.071 & 0.071 & 0.071 & 0.071 & 0.071 & 0.071 & 0.071 & 0.071 & 0.071 & 0.071 \\
\hline $\mathrm{O}_{2}$ & 0.086 & 0.086 & 0.086 & 0.086 & 0.086 & 0.086 & 0.086 & 0.086 & 0.086 & 0.086 & 0.086 & 0.086 & 0.086 & 0.086 \\
\hline $\mathrm{O}_{3}$ & 0.097 & 0.097 & 0.097 & 0.097 & 0.097 & 0.097 & 0.097 & 0.097 & 0.097 & 0.097 & 0.097 & 0.097 & 0.097 & 0.097 \\
\hline $\mathrm{O}_{4}$ & 0.068 & 0.068 & 0.068 & 0.068 & 0.068 & 0.068 & 0.068 & 0.068 & 0.068 & 0.068 & 0.068 & 0.068 & 0.068 & 0.068 \\
\hline $\mathrm{O}_{3}$ & 0.075 & 0.075 & 0.075 & 0.075 & 0.075 & 0.075 & 0.075 & 0.075 & 0.075 & 0.075 & 0.075 & 0.075 & 0.075 & 0.075 \\
\hline $\mathrm{C}_{1}$ & 0.062 & 0.062 & 0.062 & 0.062 & 0.062 & 0.062 & 0.062 & 0.062 & 0.062 & 0.062 & 0.062 & 0.062 & 0.062 & 0.062 \\
\hline $\mathrm{C}_{2}$ & 0.056 & 0.056 & 0.056 & 0.056 & 0.056 & 0.056 & 0.056 & 0.056 & 0.056 & 0.056 & 0.056 & 0.056 & 0.056 & 0.056 \\
\hline $\mathrm{C}_{3}$ & 0.061 & 0.061 & 0.061 & 0.061 & 0.061 & 0.061 & 0.061 & 0.061 & 0.061 & 0.061 & 0.061 & 0.061 & 0.061 & 0.061 \\
\hline $\mathrm{C}_{4}$ & 0.064 & 0.064 & 0.064 & 0.064 & 0.064 & 0.064 & 0.064 & 0.064 & 0.064 & 0.064 & 0.064 & 0.064 & 0.064 & 0.064 \\
\hline $\mathrm{C}_{3}$ & 0.069 & 0.069 & 0.069 & 0.069 & 0.069 & 0.069 & 0.069 & 0.069 & 0.069 & 0.069 & 0.069 & 0.069 & 0.069 & 0.069 \\
\hline $\mathrm{D}_{1}$ & 0.084 & 0.084 & 0.084 & 0.084 & 0.084 & 0.084 & 0.084 & 0.084 & 0.084 & 0.084 & 0.084 & 0.084 & 0.084 & 0.084 \\
\hline $\mathrm{D}_{2}$ & 0.095 & 0.095 & 0.095 & 0.095 & 0.095 & 0.095 & 0.095 & 0.095 & 0.095 & 0.095 & 0.095 & 0.095 & 0.095 & 0.95 \\
\hline
\end{tabular}

TABLE IV

PERFoRmance EVALUATION OF TALENTS FlOW

\begin{tabular}{|c|c|c|c|c|}
\hline Level 1 & Level 2 & weight & Dimensions & Scores \\
\hline \multirow{3}{*}{$\mathbf{R}$} & $\mathrm{R}_{1}$ & 0.050 & 0.87 & 0.044 \\
\cline { 2 - 5 } & $\mathrm{R}_{2}$ & 0.062 & 0.79 & 0.049 \\
\hline \multirow{3}{*}{ O } & $\mathrm{O}_{1}$ & 0.071 & 0.83 & 0.059 \\
\cline { 2 - 5 } & $\mathrm{O}_{2}$ & 0.086 & 0.68 & 0.058 \\
\cline { 2 - 5 } & $\mathrm{O}_{3}$ & 0.097 & 0.74 & 0.072 \\
\cline { 2 - 5 } & $\mathrm{O}_{4}$ & 0.068 & 0.77 & 0.052 \\
\hline \multirow{3}{*}{ C } & $\mathrm{O}_{5}$ & 0.075 & 0.82 & 0.062 \\
\cline { 2 - 5 } & $\mathrm{C}_{1}$ & 0.062 & 0.85 & 0.053 \\
\cline { 2 - 5 } & $\mathrm{C}_{2}$ & 0.056 & 0.72 & 0.040 \\
\cline { 2 - 5 } & $\mathrm{C}_{3}$ & 0.061 & 0.88 & 0.054 \\
\cline { 2 - 5 } & $\mathrm{C}_{4}$ & 0.064 & 0.84 & 0.054 \\
\hline \multirow{2}{*}{$\mathbf{D}$} & $\mathrm{C}_{5}$ & 0.069 & 0.76 & 0.052 \\
\cline { 2 - 5 } & $\mathrm{D}_{1}$ & 0.084 & 0.75 & 0.063 \\
\hline & $\mathrm{D}_{2}$ & 0.095 & 0.89 & 0.085 \\
\hline \multicolumn{2}{|c|}{ Total Scores } & 0.796 \\
\hline
\end{tabular}

Finally, the data of R1-R2, O1-O2, and C1-C2 can be obtained through local statistical yearbooks and scientific and technological yearbooks. And the D1-D2 value can be obtained by expert evaluation for quantitative and normalization processing.

\section{E. Output of Evaluation Results}

Output the results in accordance with AHP General Ranking Method. Finally, the calculated performance evaluation scores of system evaluation plans are obtained. For all indication weights and dimensionless values of the long-term stable matrix can be referred to in Table IV. The comprehensive score of performance evaluation of talents flow in this city obtained by combining the weight is 0.796 .

Defining the sets of performance evaluation of talents flow $\{$ bad, good, excellent $\}=\left\{(0,0.6),\left[\begin{array}{ll}0.6,0.8\end{array}\right)\right.$, $[0.8,1.0]\}$.

The result of performance evaluation of talents flow of this city is between 0.6 and 0.8 , the comprehensive evaluation is good.

\section{CONCLUSION}

\section{A. Figures and Tables}

Results from the study can be seen. Some elements have more impact on the improvement of performance of the flow of science and technology talents, such as the growth rate of important scientific and technological achievements, balance degree of Scientific and technological revenue \& scientific and technological spending, growth rate of patent application granting and the optimization degree of education reception of science and technology talents. We believe that government should take some measures to continuously attract and encourage science and technology talents and drive positive interactive development of regional economy and scientific and technological innovation. For example, formulate relevant preferential policies, pay attentions to the balance degree while increasing investment in scientific and technological undertakings, meanwhile intensify the promotion of investment in important scientific and technological achievements and patent granting, optimize the education environment for science and technology talents.

\section{ACKNOWLEDGMENT}

My greatest gratitude first and foremost goes to Director-- Zhenqiang Gao for his careful and beneficial guidance. My special thanks also go to Research Fellow Huimin Sun, who help me to get my project---- Research Project from Human Resources and Social Security Bureau of Zhejiang Province (L2011D039): Research on matching the transformation of private enterprise with development of innovated talents-----the Case on Ningbo. Then I have my fund for this paper.

I should also thank Dr. Xuemin Tong. She gave me advice to help me make sure the frame and structure of this paper. I never forget to mention my colleague Lina $\mathrm{Ma}$ in the investigation. She is so kind and gives me a lot of support.

My sincere appreciation also goes to the editor and reviewer. Without their advice, my paper could never have researched its present form.

\section{REFERENCES}

[1] Hu Ruiqing, "Comprehensive Index Evaluation Methods of Rational Flow of Science and Technology Talents and Determination of Its Weight Numbers", China Soft Science Magazine, 2006(7), pp.151-158.

[2] Ji Jianyue, Liu Yan, and Liu Baosheng, "Research on the Performance Evaluation of the Flow of Science and Technology Talents of Shandong Province", Modern Management Science, 2008(7),pp.100-102.

[3] Ji Jianyue, Liu Yan, and Liu Baosheng, "Research on the Performance Evaluation of the Flow of Science and Technology Talents in the Central Region of China Based on Factor AnalysisTaking Anhui Province as an Example", Modern Management Science, 2009(10), pp.86-88.

[4] Ye Chenxuan, and Zhang Yuanbiao, "Research on the Performance Evaluation of the Flow of Science and Technology Talents Based on Rough Set Theory", Modern Management Science, 2009(12), pp.423-425.

[5] Wu Yuhua, and Du Gang, "Management Science \& Foundation", Tianjin: Tianjin University Press, 2001.

[6] Liu Rui, Yu Jianxing, Sun Hongcai, and Tian Ping, "Introduction and Application of Super Decision-Making Software Based on ANP", System Engineering - Theory \& Practice, 2003(8), pp. 141-143.

[7] Xu Shubo, "Practical Decision-making Method-Principles of Analytic Hierarchy Process", Tianjin: Tianjin University Press, 1988.

[8] Sun Baiqing, "Theory and Application of Intelligence Decision Supporting System", Beijing:China Economic Publishing House, 2010. 


\section{RESEARCH ON PERFORMANCE EVALUATION BY IDSS BASED ON AHP}

[9] Chen, Q. and R. Yu, An IDSS development environment based on consistent language. Artificial Intelligence in Engineering, 1997. 11(2): p. 163-166. http://dx.doi.org/10.1016/S0954-1810(96)000 $\underline{26-X}$

[10] Tweedale, J., et al., Innovations in multi-agent systems. Journal of Network and Computer Applications, 2007. 30(3): p. 1089-1115. http://dx.doi.org/10.1016/j.jnca.2006.04.005

[11] Fan, X., et al., Behavior-based reputation management in P2P filesharing networks. Journal of Computer and System Sciences, 2012. 78(6): p. 1737-1750. http://dx.doi.org/10.1016/j.jcss. $\underline{2011.10 .021}$

\section{AUTHOR}

Xuelian Tang is with the Economics and Management Depatment, Ningbo Dahongying University, Xueyuan Street NO. 1, Gaoqiao Town, Ningbo, ZheJiang Province, CO 315175 China (e-mail: Candy78311@163.com).

This article is an extended and modified version of a paper presented at the International Conference on Mechanical Engineering, Automation and Material Science (MEAMS2012), held 22-23 December 2012, Wuhan, China. Received 14 February 2013. Published as resubmitted by the authors 25 March 2013. 